\title{
Using Critical Path Method for Making Process Layout of a T-Shirt within Earliest Finish Time
}

\author{
Takebira UM and Mohibullah ATM*
}

Apparel Manufacture and Technology, BGMEA University of Fashion and Technology, Dhaka, Bangladesh

\begin{abstract}
Apparel business applies different techniques to keep pace with the incremental competition conditions and changing consumer demands. The new design needs new analysis; new manufacturing technique which will take much more time. There is no practice of scientific analysis to manufacturing a new design garment. Critical path method is one of the most effective techniques which is a systematic approach to identifying and reducing manufacturing time through the earliest start time and the earliest finish time and also provides a scientific method for product manufacturing and whole production management. This study was carried out at a men's T- shirt producer i.e., a ready wear company. The current state of the production lines was analyzed within the scope of the study. Then t-shirt production lines were organized with the CPM techniques. The main strategy of CPM was estimated actual operation time by decreasing traditional manufacturing time. As a result, using of the CPM in garment manufacturing less the lead time of production time as well as the whole manufacturing system gets a new approach and also manufacturer are able to produce the product within minimum possible time and the apparel manufacturer will be able to fabricate contemporary fashion production project.
\end{abstract}

Keywords: Apparel; Critical path method; Manufacturing; SAM; Process layout

\section{Introduction}

Nowadays the apparel business faces competitiveness worldwide. For total production and shipment it may take long time, three to six months, where fashion is changing in a week. So, if the manufacturer wants to sustain the international apparel market they need to construct their product within minimum possible time. If the manufacturers are trailed to construct the contemporary fashion, fad fashion and ready-to-wear for mass market, it would be difficult to sustain in the apparel market. The research introduced a new scientific approach for production. The critical path method establishes the production flow chart with minimum possible time by reducing time from traditional method. The Critical Path Method, known under its acronym CPM, is a way of optimizing the sequence of scheduled activities, or tasks, in a project. The CPM is a scientific approach to analysis a new design for production. This is a management tool designed to ensure a project's completion on time [1]. Fashion is changing in its own cycle. The estimation of future production layout is a key factor in determining the overall performance of a new production layout: the earlier this information is known, the better production layout provides a better product within least time. The traditional practice of production time is depending on the number of operation of the garment, cycle time, operator efficiency and allowances. It takes maximum time for manufacturing using standard efficiency of the operators. The standard allowed minutes (SAM) provides the cycle time with allowances (minimum ten percent of all allowance -bundle, machine and personal) but it also deepens on worker efficiency. The SAM provides the design manufacturing time of all operation instead the critical path method (CPM) provides the bare minimum possible time for manufacturing. The critical path method saved the time from traditional method in every step of the task of the production and shipment. Typically, the process layout depends on garment design, fabric types, construction process and the quantification of the use of each dependentis extremely difficult in the first stages of the layout (mostly in the sample making and pre-production layout). Conversely, it is just in these phases that the availability of the production layout of previous product statistics is crucial, since most of the layouts that will be sustained in the next product or design are implicitly determined by the choices made during the elaboration of the concept and the detailed design of the new product. For this reason, different techniques approaches have been developed to cope with the problem of the estimation of manufacturing system in highly uncertain perspectives. In particular, this article demonstrated the results of a study aimed at the application of critical path method: the critical path method which has known great distribution in manufacturing system in very different application contexts. The critical path is a sequence of individual activities of a project that must be finished on schedule so that the whole project is completed on time. Activities along the path cannot begin until a predecessor activity is complete (Figure 1).

The critical path is a sequence of individual activities of a project that must be finished on schedule so that the whole project is completed on time. Activities along the path cannot begin until a predecessor activity is completed. The critical path method was developed at the DuPont Company in 1957 by a pair of mathematicians who were looking at ways to avoid the costs of plant shutdowns and restarts caused by inefficient scheduling. In this sense, the process view of the firm can be of great help in making designers and product engineers more aware of the critical role played in determining the overall economic performance of the factory, as proved by the "life cycle Lay out" theory. Indeed, the life cycle theory states that, although the great majority of product design depends on basic design. Most of these lay out are implicitly determined in the early phases of development. Their

*Corresponding author: Mohibullah ATM, Apparel Manufacture and Technology, BGMEA University of Fashion and Technology, Dhaka, Bangladesh, Tel: +880 2-8919986; E-mail: mohib@buft.edu.bd

Received August 28, 2017; Accepted September 06, 2017; Published September 10, 2017

Citation: Takebira UM, Mohibullah ATM (2017) Using Critical Path Method for Making Process Layout of a T-Shirt within Earliest Finish Time. J Textile Sci Eng 7 : 316. doi: 10.4172/2165-8064.1000316

Copyright: @ 2017 Takebira UM, et al. This is an open-access article distributed under the terms of the Creative Commons Attribution License, which permits unrestricted use, distribution, and reproduction in any medium, provided the original author and source are credited. 


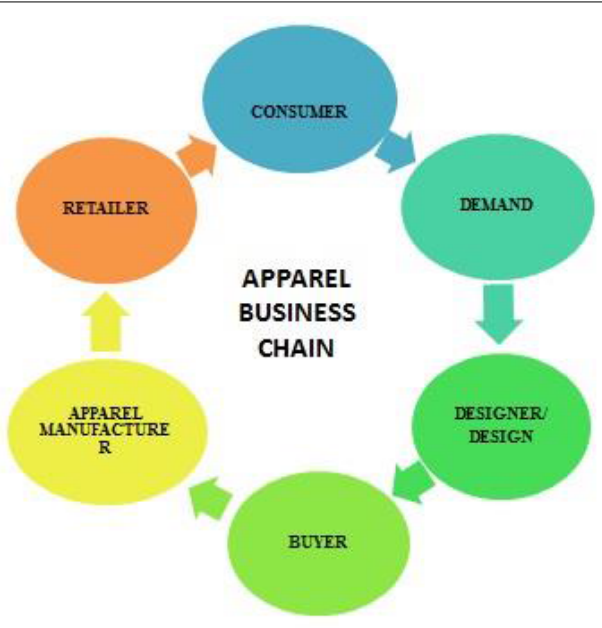

Figure 1: Apparel business chain.

research demonstrated that money could be saved by focusing efforts on performing the right tasks at the right times, rather than flooding the problem with labor to stay on schedule. Just- in-time strategy ensures that customer-specific needs are satisfied. Customer satisfaction is the key to success in any businesss [2]. The growing competition from low-cost regions has become an increasing concern for manufacturer in most industrialized countries. Drawing on the contingency theory, researchers agree that firms should seek a better fit with their customers' need as it will result in better performance of their operations [3]. The standardized style is related to the dimension of cost. Significant associations were also found between the multiple-sewing systems used by plants and dimensions of manufacturing strategy (cost, delivery, and flexibility) [4]. CPM (Critical Path Method) was developed by Kelly JE and Walkerin MR order to help the construction and maintenance of chemical plant in Dupont. PERT was developed for planning and controlling of the processes. CPM method was developed by adding cost of the processes to planning and controlling in the method of PERT. CPM assumes that the durations of the activities are definitely determined. According to CPM, each project has a critical path which comprises of the activities that may delay the entire project in case of a delay in the start, finish or completion [5]. Nowadays, the concept of change and development in fashion has increased the volatility of customer demands extremely. In recent years, the concept of the few model variety-high quantity orders has turned into numerous model variety-low quantity orders. At the same time, the era of competing with quality and cost is replaced with the era of competing through speed, service and innovation [6]. CPM provides a graphical representation of the project and predicts its completion time [1]. Being constituted mainly by people with technical or scientific competencies, during the new product development (NPD) process this unit traditionally puts much more emphasis on the technologically innovative contents and on the absolute performance of the product, then on the impact of the adopted solutions on the economics and on related figures (like the manufacturing costs or the contribution margin generated by the new product).

\section{Hypothesis}

If we use the critical path method for garment parts preparing and assembling, it will introduce the process breakdown and process flow chart with least possible time. The steps will be analyzed how long each operation will take time. The critical path method will not allow beginning any step until its predecessor steps are completed; each step has to possess an earliest possible start and finishes time- based on the estimated time it will take to complete the preceding steps. Critical proceedings on the CPM chart must be done on time. All non-critical events will have some amount of slack; even if it takes a bit longer than expected to complete a non-critical event, it won't delay the project as a whole. The standard allowed minutes (SAM) gives the cycle time with bundle, machine and personal allowances (minimum ten percent) but it will also be contingent on worker efficiency. The SAM provides the garment design manufacturing time of all operation conversely the critical path method (CPM) will provide the hasty possible time for manufacturing using the same allowances and same worker efficiency. The lead time of garment manufacturing will be less. If we change the activity, immediate predecessors ( $\mathrm{t}$-shirt operations) as independent variables it will furnish the earliest finish time, process layout and machine layout multivariate where basic time and allowances are constant variables [7].

\section{Materials and Methods}

The purpose of the research was to compare the results achieved with the application of a traditional process layout technique with those obtained through the design and implementation of a network diagram (CPM). In application of traditional method the Standard Allowed Minutes for a basic t-shirt is 637 seconds or 6.37 minutes where the basic time is 490 seconds or 4.9 minutes at $91 \%$ performance rating by using $10 \%$ of bundle, machine and personal allowances (total $30 \%$ ). The analysis was conducted through a real case study provided by a knit garment factory manufacturing basic $t$-shirt. The main mission of the company is the design, Production according to buyer demands. In particular, this study focuses on the estimation of manufacturing time of a garment as well as the manufacturing time using minimum work station with least possible time (Table 1).

The study was conducted a review of the literature on critical path method using apparel manufacturing in order to develop research hypotheses. The study was intended to confine the current status of all the system of critical path method where we find out the potential method of manufacturing. It was also conducted an experiment by using the production lines of a t-shirt. The production lines were organized with the critical path method techniques by using the operations breakdown as independent variables name activity and immediate predecessor. The experiment was provided multivariate-

\begin{tabular}{|c|c|c|c|c|}
\hline Activity & Operation & $\mathrm{M} / \mathrm{C}$ & $\begin{array}{l}\text { Basic time } \\
\text { without } \\
\text { allowance }\end{array}$ & $\begin{array}{c}\text { Basic time } \\
\text { with } 30 \% \\
\text { allowance }\end{array}$ \\
\hline A. & Sleeve hem & $\mathrm{F} / \mathrm{L}$ & $40 \mathrm{~s}$ & $52 s$ \\
\hline B. & Join the collar rib & SNL & $14 s$ & $18.2 \mathrm{~s}$ \\
\hline C. & Open the seam and tack & SNL & $16 s$ & $20.8 s$ \\
\hline D. & Join shoulder & $\mathrm{O} / \mathrm{L}$ & $38 s$ & $49.4 \mathrm{~s}$ \\
\hline E. & Attach the collar rib to body & $\mathrm{O} / \mathrm{L}$ & $48 s$ & $62.4 \mathrm{~s}$ \\
\hline F. & Attach the main label & SNL & $28 s$ & $36.4 \mathrm{~s}$ \\
\hline G. & $\begin{array}{l}\text { Attach tape to collar, fold \& } \\
\text { cut tap }\end{array}$ & $\begin{array}{l}\text { SNL } \\
\text { (Fldr.) }\end{array}$ & $66 s$ & $85.8 s$ \\
\hline $\mathrm{H}$. & Close the neck tape & SNL & $43 s$ & $55.9 s$ \\
\hline I. & Attach sleeve & $\mathrm{O} / \mathrm{L}$ & $56 s$ & $72.8 \mathrm{~s}$ \\
\hline J. & Side seam with care label & $\mathrm{O} / \mathrm{L}$ & $65 s$ & $84.5 \mathrm{~s}$ \\
\hline K. & Bottom hemming & $\mathrm{F} / \mathrm{L}$ & $48 s$ & $62.4 \mathrm{~s}$ \\
\hline \multirow[t]{2}{*}{ L. } & Tack sleeve & SNL & $28 s$ & $36.4 \mathrm{~s}$ \\
\hline & Total & & $\begin{array}{c}\text { 490s\& SMV } \\
6.37 \text { minutes } \\
(637 \mathrm{~s})\end{array}$ & $637 s$ \\
\hline
\end{tabular}

Table 1: Process breakdown of t-shirt. 
critical path for process flow, earliest finish time and machine layout. The basic time and the allowances were used as constant variables. A model was developed for process layout. The experiment provided the process layout with minimum manufacturing time. To conduct a CPM analysis, begin by listing all the tasks required to complete the project. The next step was estimate how long each task was taken. There was no step begins until its predecessor steps were completed; each step had an earliest possible start and finish time based on the estimated time it took to complete the preceding steps. Some steps had earliest start times identical to their latest start times. These were the critical events in the task. Using the CPM we find the critical path, add up the time needed to complete each step to find out how long the task as a whole should take. A critical event on the CPM chart was done on time (Table 2).

There were no immediate predecessor of $\mathrm{A}, \mathrm{B}, \mathrm{D}$ tasks (sleeve hem, join the collar rib, join shoulder). B/join the collar rib task must be finished before C/open the seam and tack task can start. Both $\mathrm{C} /$ open the seam and tack task and D/join shoulder task must be finished before E/attach the collar rib to body task can start. Before F/attach the main label task started E/attach the collar rib to body task must be finished. F/attach the main label task must be finished before G/attach tape to collar, fold and cut tap task can start. G/attach tape to collar, fold \& cut tap task must be finished before $\mathrm{H} /$ close the neck tape task can start. Both $\mathrm{H} /$ close the neck tape task and $\mathrm{A} /$ sleeve hem task must be finished before I/attach sleeve task can start. I/attach sleeve task must be finished before J/side seam with care label task can start.J/side seam with care label task must be finished before K/bottom hemming task can start. K/bottom hemming task must be finished before $\mathrm{L} /$ tack sleeve task can start (Figure 2).

\section{Data Analysis}

$\mathrm{A} /$ sleeve hem, $\mathrm{B} /$ join the collar rib and $\mathrm{D} /$ join shoulder tasks' earliest finished time (EF)-52, 18.2 and 49.4. C/open the seam and tack task's earliest start time (ES) is 18.2, task duration ( $\mathrm{t}$ ) is 20.8 and its earliest finish time is $39\{\mathrm{EF}=\mathrm{ES}+\mathrm{A}(\mathrm{t}) \text { so, } \mathrm{EF}=18.2+20.8=39\}^{*}$. Both C/ open the seam and tack task and D/join shoulder task must be finished before E/attach the collar rib to body task can start. So, E/attach the collar rib to body task's earliest start time is 49.4 and its earliest finish time is 111.8 the task's duration $(\mathrm{t})$ is $62.4\{\mathrm{EF}=\mathrm{ES}+\mathrm{A}(\mathrm{t})$ so, $\mathrm{EF}=49.4$ $+62.4=111.8\}^{*}$. F/attach the main label task's earliest start time is 111.8 and its earliest finish time is 148.2 the task's duration $(\mathrm{t})$ is 36.4 $\{\mathrm{EF}=\mathrm{ES}+\mathrm{A}(\mathrm{t}) \text { so, } \mathrm{EF}=111.8+36.4=148.2\}^{*}$. G/attach tape to collar, fold \& cut tap task's earliest start time is 148.2 and its earliest finish time is 234 the task's duration $(\mathrm{t})$ is $85.8\{\mathrm{EF}=\mathrm{ES}+\mathrm{A}(\mathrm{t})$ so, $\mathrm{EF}=148.2+85.8$ $=234\}^{*} . \mathrm{H} /$ close the neck tape task's earliest start time is 234 and its earliest finish time is 289.9 the task's duration $(\mathrm{t})$ is 55.9 \{EF=ES+A (t) so, $\mathrm{EF}=234+55.9=289.9\}^{*}$. Though Both $\mathrm{H} /$ close the neck tape task and A/ sleeve hem task must be finished before I/attach sleeve task can start, so I/attach sleeve task's earliest start time is 289.9 and its earliest finish time is 362.7 the task's duration $(\mathrm{t})$ is 72.8 . J/side seam with care label task's earliest start time is 362.7 and its earliest finish time is 447.2 the task's duration $(\mathrm{t})$ is 84.5 . K/bottom hemming task's earliest start time is 447.2 and its earliest finish time is 509.6 the task's duration $(\mathrm{t})$ is 62.4. Finally, for finished task L/tack sleeve takes 36.4 its earliest start time is 509.6 and its earliest finish time is 546 (Figures 3 and 4).

\section{Result}

Task L/tack sleeve take's latest finish time (LF) 546 and its latest start time (LS) is $509.6 . \mathrm{K} /$ bottom hemming task's latest finish time

\begin{tabular}{|c|c|c|c|c|c|c|c|c|c|c|c|c|}
\hline Activity & A & B & C & D & $E$ & $\mathbf{F}$ & G & $\mathbf{H}$ & $\mathbf{I}$ & $\mathbf{J}$ & $\mathbf{K}$ & $\mathbf{L}$ \\
\hline Immediate Predecessor & - & - & $B$ & - & C,D & $E$ & $\mathrm{~F}$ & G & $\mathrm{H}, \mathrm{A}$ & 1 & $\mathrm{~J}$ & $\mathrm{~J}, \mathrm{~K}$ \\
\hline Time & 52 & 18.2 & 20.8 & 49.4 & 62.4 & 36.4 & 85.8 & 55.9 & 72.8 & 84.5 & 62.4 & 36.4 \\
\hline
\end{tabular}

Table 2: Activity, immediate predecessor and time by using the t-shirt operation breakdown.

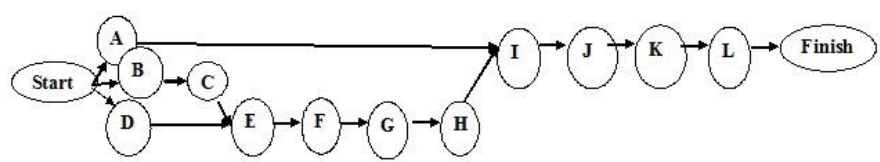

Figure 2: Critical path method of the t-shirt manufacturing

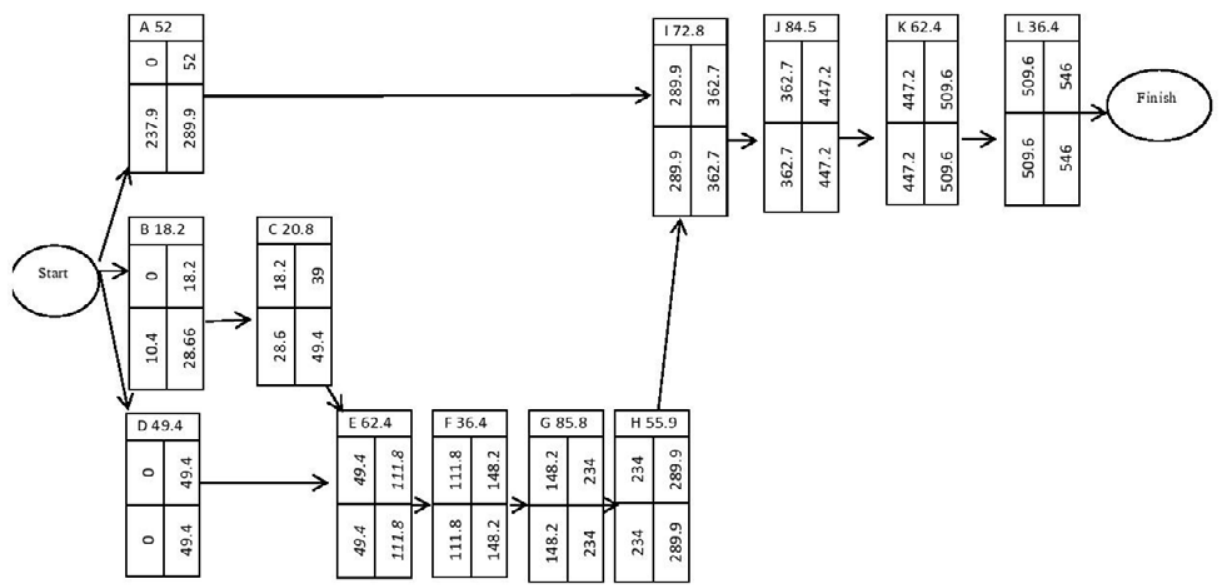

Figure 3: Critical path method D-E-F-G-H-I-J-K-L. 


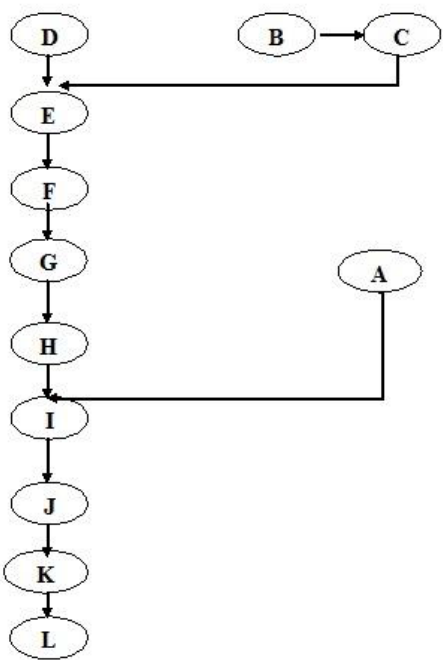

Figure 4: T-shirt process layout by using CPM.

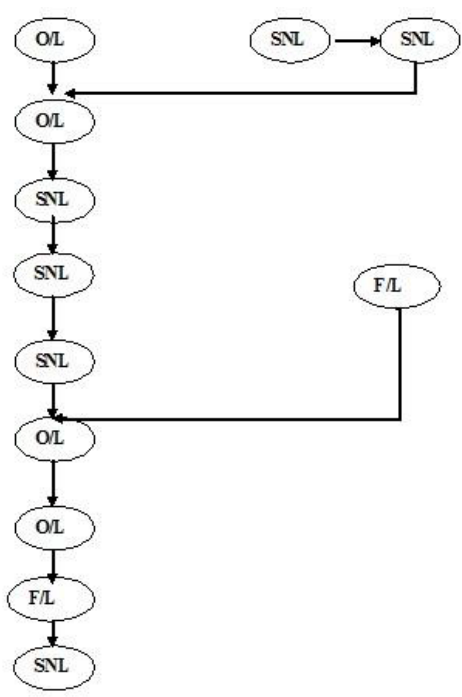

Figure 5: T-shirt machine layout by using CPM

509.6 and its latest start time is $447.2 . J /$ side seam with care label task's latest finish time 447.2 and its latest start time is 362.7.I/attach sleeve task's latest finish time 362.7 and its latest start time is $289.9 . \mathrm{H} /$ close the neck tape task's latest finish time 289.9 and its latest start time is 234.G/attach tape to collar, fold \& cut tap task's latest finish time 234 and its latest start time is 148.2 .F/attach the main label task's latest finish time 148 and its latest start time is 111.8.E/ attach the collar rib to body task's latest finish time 111.8 and its latest start time is $49.4 . \mathrm{C} /$ open the seam and tack task's latest finish time 49.4 and its latest start time is 28.6 .A/sleeve hemtask's latest finish time 289.9 and its latest start time is $237.9 . \mathrm{B} /$ join the collar ribtask's latest finish time 28.6 and its latest start time is 10.4 and $\mathrm{D} /$ join shoulder tasks' latest finish time 49.4 and its latest start time is 0 .The result provides the earliest finish time within 546 seconds where SAM is 637 seconds. The study reduces the manufacturing time (637-546) 91 seconds. The critical path (ES$\mathrm{LS}=0){ }^{*} \mathrm{D}-\mathrm{E}-\mathrm{F}-\mathrm{G}-\mathrm{H}-\mathrm{I}-\mathrm{J}-\mathrm{K}-\mathrm{L}$. The critical path provides the process flow chart as well as machine layout by balancing the production line in a scientific approach with earliest possible finish time.

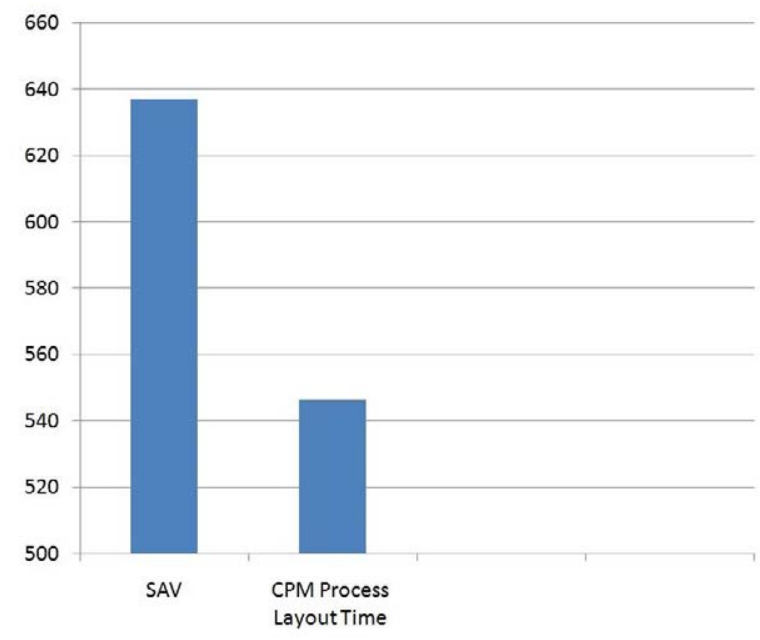

Figure 6: An analysis of SAM and CPM process time.

The purpose of the research was to compare the results achieved with the application of a traditional process layout technique with those obtained through the design and implementation of a network diagram. In reality, the main references found are the following: an analysis of the results of the application of traditional method the standard allowed minutes for a basic $\mathrm{t}$-shirt is 637 seconds where the basic time is 490 seconds at $91 \%$ performance rating by using 10 $\%$ allowances. In particular, this result focuses on the estimation of manufacturing time of a t-shirt as well as the manufacturing time reduction 91 seconds from the traditional time using minimum work station (Figures 5 and 6).

\section{Conclusion}

The apparel manufacturer needs to capture the cycle where the fashion is changing in a week. The political issue, technological issue, social influences and the economical influences change the fashion. So, as early as possible it is needed to develop the production method by using scientific approach where using technology to consume led time for production. It is noted that the sewing department takes more time for preparing and assembling of garment for using traditional method of process flow. The developing countries and the low-middle income countries apparel manufacturers export Ready-Made-Garment to the developed countries who are the fashion leaders world-wide. To sustain in the international apparel businesses it will be needed scientific approach using technological method for production to consume the lead time or else the apparel business will be only for classic fashion for low and medium category product. If the traditional method is going on the international apparel business will back to the history when the business was for uniform for low-middle income countries. To sustain in the apparel business the manufacturers need to produce the classic and popular fashion and need to be able to produce fad fashion and also prêt-a-porter, fashion for mass market. The earliest finished production time is able to produce all fashion by reducing traditional time as well as cost of the product. It will also reduce cost of production and the product will be at the right time in the market.

\section{References}

1. Kielmas M (2015) History of the Critical Path Method. Small Business. Chron Com Demand Media.1

2. Yeung AH, Lo VH, Yeung AC, Cheng TE (2008) Specific customer knowledge 
Citation: Takebira UM, Mohibullah ATM (2017) Using Critical Path Method for Making Process Layout of a T-Shirt within Earliest Finish Time. J Textile Sci Eng 7: 316. doi: 10.4172/2165-8064.1000316

Page 5 of 5

and operational performance in apparel manufacturing. International Journal of Production Economics 114:520-533.2

3. Lin SH, Moore MA, Kincade DH, Avery C (2002) Dimensions of apparel manufacturing strategy and production management. International Journal of Clothing Science and Technology 14: 46-60.4

4. Das A, De D (2000) Nutritive value of Guatemala grass (Tripsacumlaxum) as affected by method of conservation. J Hill Res 13: 119-121.4
5. Guner M (2006) Konfeksiyon İşletmelerinde Organizas yonve Planlama.EgeÜn iversitesiMühendislikFakültesiTekstilMühendisliğiBölümü: 103-124.5

6. Christopher M (2000) The agile supply chain: competing in volatile markets Industrial Marketing Management 29: 37-44.6

7. Cavalieri S, Maccarrone P, Pinto R (2004) Parametric vs. neural network models for the estimation of production costs: A case study in the automotive industry. International Journal of Production Economics 91: 165-177. 